\title{
Microstructure characterization in the weld metals of HQ130 + QJ63 high strength steels
}

\author{
WANG JUAN and LI YAJIANG* \\ Key Laboratory of Liquid Structure and Heredity of Materials, Ministry of Education, School of Materials Science \\ and Engineering, Shandong University, Jinan 250061, P.R. China
}

MS received 27 November 2002

\begin{abstract}
Microstructural characterization of the weld metals of HQ130 + QJ63 high strength steels, welded under $80 \% \mathrm{Ar}+20 \% \mathrm{CO}_{2}$ gas shielded metal arc welding and different weld heat inputs, was carried out by means of scanning electron microscopy (SEM) and transmission electron microscopy (TEM). The relative contents of acicular ferrite (AF) and pro-eutectic ferrites (PF) in the weld metals were evaluated by means of XQF-2000 micro-image analyser. The experimental results indicate that there is acicular ferrite in the grain and some pro-eutectic ferrite on the boundary of original austenite grains when the weld heat input is small $(E=9.6 \mathrm{~kJ} / \mathrm{cm})$, but the main microstructure is ferrite side plate (FSP) when the heat input is larger $(E=22.3 \mathrm{~kJ} / \mathrm{cm})$. So the weld heat input should be strictly controlled in the range $10 \sim 20 \mathrm{~kJ} / \mathrm{cm}$ and then the content of pro-eutectic ferrite is limited to $<25 \%$. Thus weld metals of HQ130 + QJ63 high strength steels with high toughness and excellent resistance to cracking can be ensured.
\end{abstract}

Keywords. Microstructure characterization; high strength steel; weld metals.

\section{Introduction}

With the development of modern industry, there is an increasing demand for high strength steels. At the same time, high strength steels demand higher welding quality. The key problem in welding high strength steel structure is to ensure adequate strength and toughness in the weld metals (Jiao 1994; Zhang et al 1995). Especially for low alloy high strength steel whose tensile strength $\sigma_{\mathrm{b}} \geq 1000 \mathrm{MPa}$, it is more important to both maintain the strength and improve the toughness in the weld metals (Zou and Li 1999). HQ130 high strength steel has tensile strength, about $1300 \mathrm{MPa}$. It is used in shovel body of engineering loading machines, while QJ63 steel is commonly used in engineering machines. It is therefore essential to join HQ130 (as knife edge plate) and QJ63 (shovel body) high strength steels in engineering applications. The performance of the whole weld joint is determined by the microstructure in the weld metals (Liu and Olson 1986; Kluken 1991). At present, studies on microstructure and performance of weld joints are mainly limited to lower strength grades $\left(\sigma_{\mathrm{b}} \leq 800 \mathrm{MPa}\right)$. Studies on microstructure and performance in higher strength grades $\left(\sigma_{\mathrm{b}} \geq 1000 \mathrm{MPa}\right)$ are few (Grong and Matlock 1986; Yin et al 1987; Oldland et al 1989). Previously the microstructure analysis was only qualitative (by means of traditional metallography), and the results were less accurate and not easily reproducible. With the wide

*Author for correspondence application of computer technology in the field of welding, complicated microstructures in the weld metals can be analysed quantitatively through several observation fields by means of a computer. Thus the effect on measured results by artificial factors is decreased and the relation between weld process and microstructure and performance of the weld metal can be indicated quantitatively.

In this paper, microstructures in the weld metals for HQ130 + QJ63 high strength steels, welded by gas shielded metal arc welding under different weld heat inputs, was investigated by SEM and TEM. Temperature distribution with different cooling times was calculated. The relative contents of acicular ferrite (AF) and proeutectic ferrite (PF) in the weld metals was evaluated by means of computer micro-image analyser. The process involved in the formation of $\mathrm{AF}$ in the weld metals and the effect of AF on the cracking behaviour are further investigated. This is useful in understanding the relationship between the microstructure and performance and setting the best welding technology parameters in production. Furthermore, such studies will help in the development of weld metals with good strength and toughness.

\section{Experimental}

The materials used in the present work are HQ130 and QJ63 quenched-tempered high strength steel sheets of $12 \mathrm{~mm}$ thickness. The chemical composition and mechanical properties of the two steels are shown in table 1. Before welding, single "V" groove $\left(60 \pm 5^{\circ}\right)$ was 
made in the weld joint. HQ130 and QJ63 steels were welded together from both sides by employing $80 \%$ $\mathrm{Ar}+20 \% \mathrm{CO}_{2}$ gas shielded metal arc welding. Different strength grade welding materials, such as GHS-80, GHS70, GHS-60, GHS-50 wires were used during welding. But the results indicate that the hardenability of HQ130 + QJ63 steels is so large that cracking rate is above 50\% when welded by GHS-80, GHS-70, GHS-60 wires under the condition of no preheating welding. In this paper, the samples tested were from crack-free welds prepared using GHS-50 wire under the condition of no preheating welding. The chemical composition and mechanical properties of GHS-50 wire are also shown in table 1. The weld heat input $(E)$ in the test was $9.6 \mathrm{~kJ} / \mathrm{cm}, 16.0 \mathrm{~kJ} / \mathrm{cm}$ or $22.3 \mathrm{~kJ} / \mathrm{cm}$.

The microstructures in the weld metals were observed by means of light microscopy, scanning electron microscopy (SEM) and transition electron microscopy (TEM). The temperature field in the welding fusion pool of HQ130 steel was calculated by means of finite difference technology, through a program of numerical analysis in FORTRAN77 and according to the controlling equations of temperature field in the fusion pool by MIG/MAG welding under kinetic plotting system. The temperature distribution in the weld joint of HQ130 + QJ63 steels was formulated for cooling times of $0 \mathrm{~s}, 0.5 \mathrm{~s}$ and $1.5 \mathrm{~s}$. The microstructural constituents in the weld metals were evaluated by means of XQF-2000 micro-image analyser.

\section{Results and analysis}

\subsection{Microstructure in the weld metals of HQ130+QJ63 steels}

The microstructural features in the welds of HQ130+ QJ63 high strength steels are shown in figure 1. The main constituents are fine acicular ferrites (AF) inside the grains and some pro-eutectic ferrite $(\mathrm{PF})$ distributed on the boundary of the original austenite (see figure 1a). But with increasing weld heat input, pro-eutectic ferrite grows into the grains in the shape of lath, forming ferrite side plate (FSP) (see figure 1b). This is unfavourable to the performance of weld metals because ferrite side plate is coarser and longer than $\mathrm{AF}$ and $\mathrm{PF}$.

Temperature distribution in the fusion pool determines the microstructures formed in the weld metals. Microstructure type and features are controlled by the details of rapid fusion, solidification and cooling. The relation between the temperature distribution in the welding fusion pool and the cooling time $(t)$ is shown in figure 2 .

According to the temperature distribution in the fusion pool, first transition of pro-eutectic ferrite and its nucleation on the boundary of austenite will occur during cooling. Thus a large number of carbon atoms are squeezed out and get distributed in the interface between ferrite and austenite. When the weld heat input is larger, the small number of FSP formed on the boundary grow into the grains and there exists a constituent with higher carbon between laths with decreasing temperature.

\subsection{Fine structure of acicular ferrite}

TEM analysis of the weld metals of HQ130 + QJ63 high strength steel was conducted in order to demonstrate the importance of microstructural features in acicular ferrite and in understanding the mechanism of improvement of toughness in the weld metals. The TEM morphology of acicular ferrite is shown in figure 3 .

From figure 3 , we can find that acicular ferrite in the weld metals consists of a substructure and the substructure contains a large dislocation density. The acicular ferrites interlude with each other in the shape of a large angle grain boundary, which is favourable to prevent crack propagation. In addition, there are a few rod-like constituents in the boundary of acicular ferrite, which are

Table 1. Chemical composition and mechanical properties of HQ130 and QJ63 steels and GHS-50 wire.

\begin{tabular}{|c|c|c|c|c|c|c|c|c|c|c|c|c|}
\hline \multirow[b]{2}{*}{ Materials } & \multicolumn{12}{|c|}{ Chemical compositions (\%) } \\
\hline & $\mathrm{C}$ & $\mathrm{Si}$ & $\mathrm{Mn}$ & Mo & $\mathrm{Cr}$ & $\mathrm{Ni}$ & B & $S$ & $\mathrm{P}$ & V & $\mathrm{N}$ & $\operatorname{Re}$ \\
\hline HQ130 & $0 \cdot 18$ & $0 \cdot 29$ & $1 \cdot 21$ & $0 \cdot 28$ & $0 \cdot 61$ & 0.03 & $0 \cdot 0012$ & 0.006 & $0 \cdot 025$ & - & - & - \\
\hline QJ63 & $0 \cdot 15$ & $0 \cdot 40$ & $1 \cdot 48$ & 0.46 & - & - & - & 0.015 & $0 \cdot 017$ & $0 \cdot 05$ & $0 \cdot 02$ & $0 \cdot 15$ \\
\hline \multirow[t]{2}{*}{ GHS-50 } & $0 \cdot 08$ & $0 \cdot 40$ & $1 \cdot 10$ & - & - & - & - & - & - & - & - & - \\
\hline & \multicolumn{12}{|c|}{ Mechanical properties } \\
\hline Materials & \multicolumn{2}{|l|}{$\sigma_{\mathrm{b}}(\mathrm{MPa})$} & \multicolumn{2}{|l|}{$\sigma_{\mathrm{b}}(\mathrm{MPa})$} & \multicolumn{2}{|l|}{$\delta_{5}(\%)$} & \multicolumn{2}{|c|}{$\psi(\%)$} & \multicolumn{2}{|l|}{$\mathrm{HRC}$} & \multicolumn{2}{|c|}{$A_{\mathrm{KV}}(\mathrm{J})$} \\
\hline HQ130 & \multicolumn{2}{|l|}{1370} & \multicolumn{2}{|l|}{1313} & \multicolumn{2}{|l|}{10} & \multicolumn{2}{|c|}{43} & \multicolumn{2}{|l|}{$40 \cdot 5$} & \multicolumn{2}{|c|}{64} \\
\hline QJ63 & \multirow{2}{*}{\multicolumn{2}{|c|}{830}} & \multicolumn{2}{|l|}{760} & \multicolumn{2}{|l|}{14} & \multicolumn{2}{|c|}{41} & \multicolumn{2}{|l|}{25} & \multicolumn{2}{|c|}{72} \\
\hline GHS-50 & & & \multicolumn{2}{|l|}{420} & \multicolumn{2}{|l|}{25} & \multicolumn{2}{|c|}{38} & \multicolumn{2}{|l|}{-} & \multicolumn{2}{|c|}{140} \\
\hline
\end{tabular}


identified by means of electron diffraction to be residual austenite rich in carbon and nitrogen.

The nature of acicular ferrite in the weld metals is bainitic and corresponds to mid-temperature phase transformation (Wang et al 1990). Optical microscopy has revealed that acicular ferrite lies in the original austenitic grain with fine and inter-link lath compositions, which grow radially. Acicular ferrite is formed in the weld during the transition from austenite to ferrite. The path for crack propagation in acicular ferrite is so flexuous that the energy needed for crack growth is more. The welds therefore exhibit higher toughness. But pro-eutectic ferrite is the product of solid austenite undergoing phase change, after the weld produces austenite with columnar grains during solidification and crystallization (Li et al 1997). The pro-eutectic ferrite has low angle boundaries leading to coarse and directional grain growth, which is unfavourable to good impact toughness.

If acicular ferrite grain is finer, the energy necessary for crack propagation will be more because of the flexural
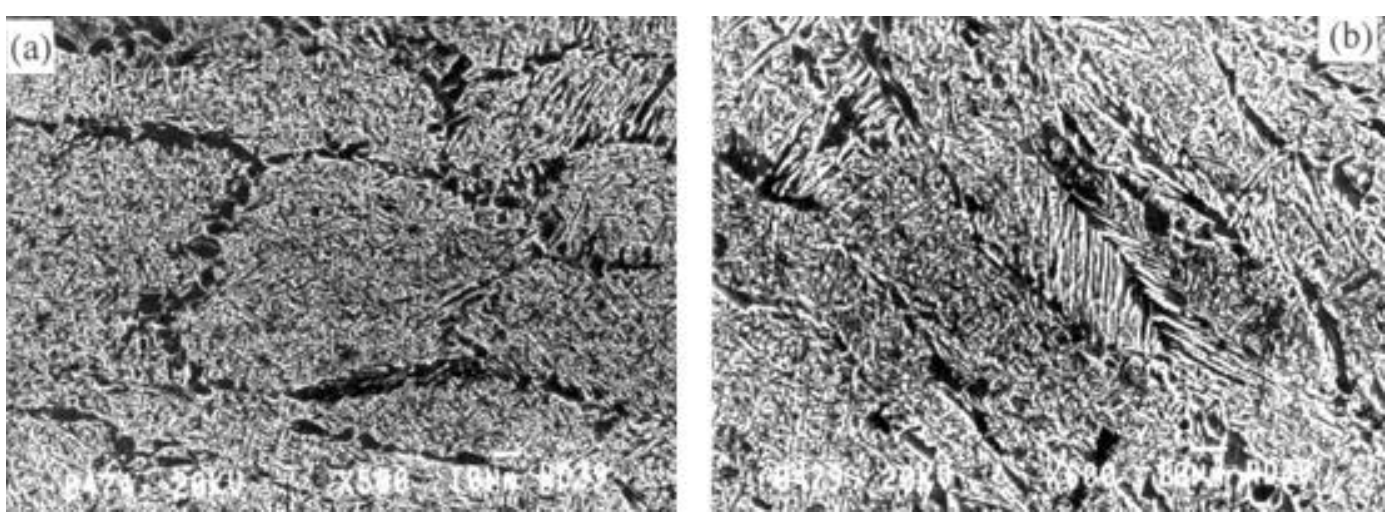

Figure 1. Scanning electron micrographs of the HQ130+QJ63 welds. (a) AF and PF, $E=9.6 \mathrm{~kJ} / \mathrm{cm}(\times 500)$ and (b) FSP, $E=22.3 \mathrm{~kJ} / \mathrm{cm}(\times 600)$.
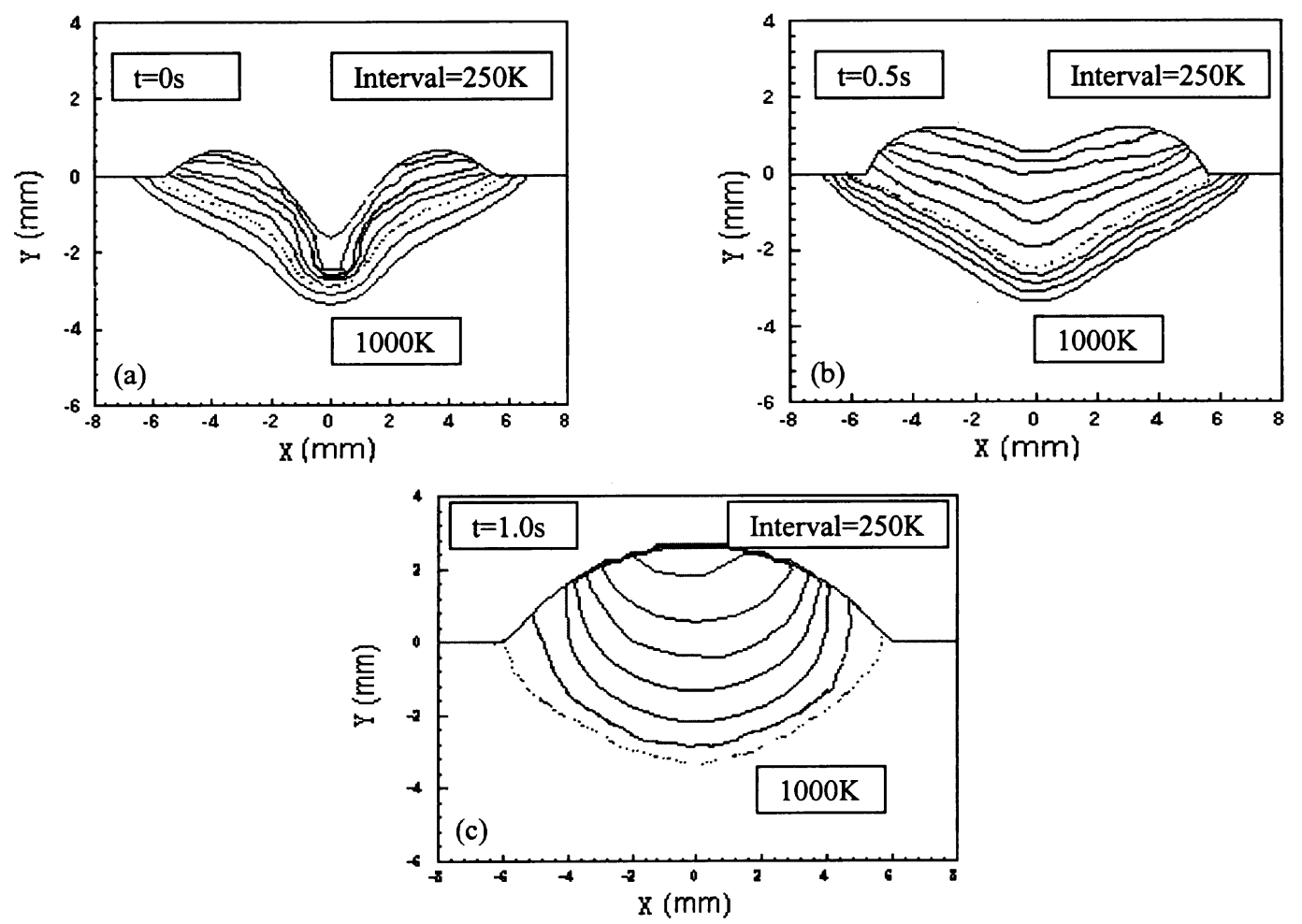

Figure 2. Temperature distribution in the fusion pool with different cooling times: (a) $t=0 \mathrm{~s}$, (b) $t=0.5 \mathrm{~s}$ and $(\mathbf{c}) t=1.0 \mathrm{~s}$. 

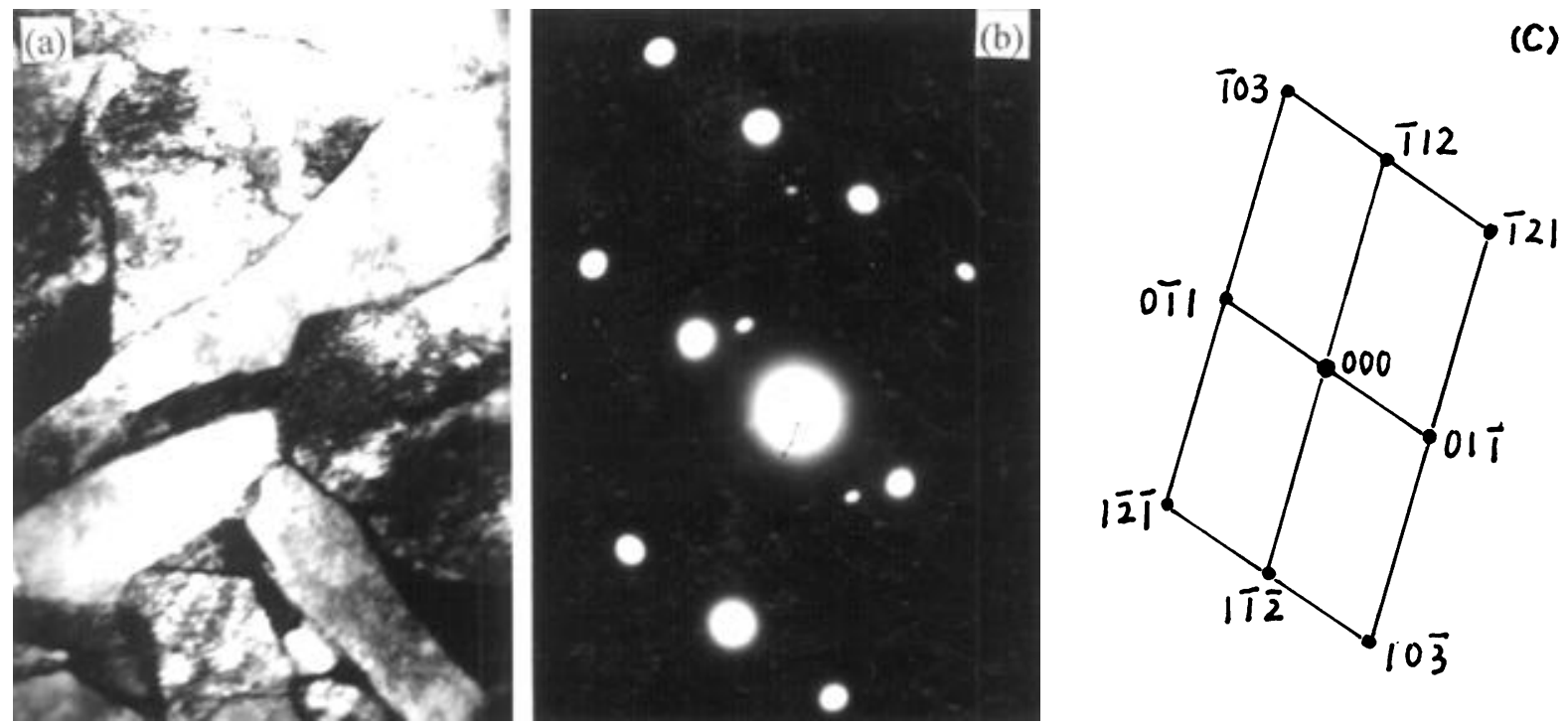

Figure 3. TEM morphology of acicular ferrite (AF) in the weld metals of HQ130 + QJ63 high strength steels: (a) TEM morphology $(\times 20,000)$, (b) electron diffraction pattern and (c) schematic diagram, $B=[311]$.

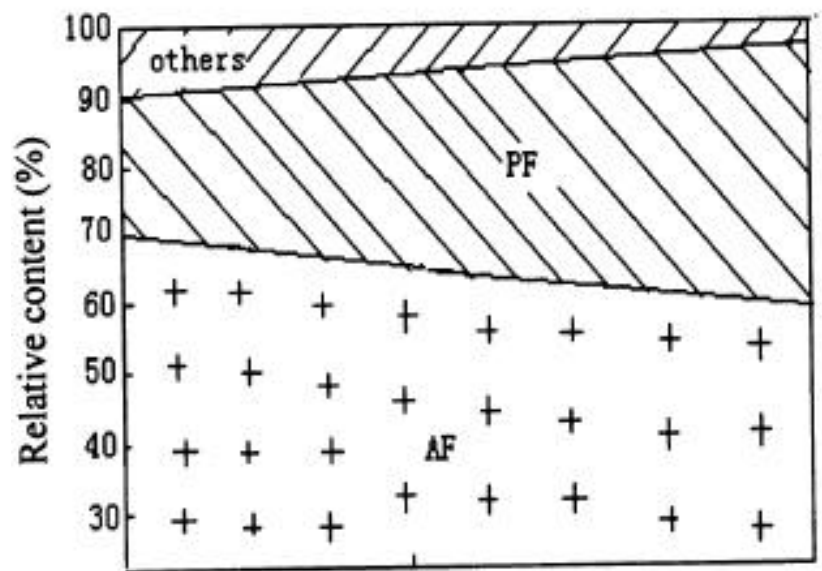

9.6
22.3

\section{Weld heat input $(\mathrm{kJ} / \mathrm{cm})$}

Figure 4. Variation of the relative proportion of phases with weld heat input.

path the propagating crack takes. Hence, the proportion of acicular ferrite and pro-eutectic ferrite determines the crack growth resistance and the impact toughness of the weld metals. The higher the proportion of acicular ferrite, the lower is the ductile-brittle transition temperature and higher is the impact toughness of the weld. Higher proportion of pro-eutectic ferrite results in higher transition temperature and lower impact toughness (Farrar and Harrison 1987). The content of acicular ferrite is determined by the weld heat input. The relative proportion of these phases in the microstructure is shown in figure 4 as a function of the weld heat input.
It is clear from figure 4 that with increase in the weld heat input, the content of acicular ferrite in the weld decreases while the content of coarse pro-eutectic ferrite becomes larger. This will impair the impact toughness. For a weld heat input of $22.3 \mathrm{~kJ} / \mathrm{cm}$, the content of proeutectic ferrite is up to $30.5 \%$ and the impact toughness measured by V-type notch impact test is as low as $72 \mathrm{~J}$. In order to resist cold cracking and prevent brittleness in the heat affected zone, the weld heat input should be controlled in the range $10 \sim 20 \mathrm{~kJ} / \mathrm{cm}$, so that the proeutectic ferrite in the weld is limited to $<25 \%$. Thus it is possible to produce welds with a high toughness.

\section{Conclusions}

(I) The weld microstructure contains acicular ferrite within the grains and some pro-eutectic ferrite on the boundary of original austenite grains when the weld heat input is small $(E=9.6 \mathrm{~kJ} / \mathrm{cm})$; however, the main phase in the microstructure is ferrite side plate (FSP) when the heat input is larger $(E=22 \cdot 3 \mathrm{~kJ} / \mathrm{cm})$.

(II) Acicular ferrite in the weld metals possesses a substructure wherein a large dislocation density is present. The acicular ferrites interlude each other in the shape of large angle grain boundaries. In addition, there is residual austenite rich in carbon and nitrogen.

(III) The weld heat input should be strictly controlled in the range of $10 \sim 20 \mathrm{~kJ} / \mathrm{cm}$ when welding HQ130 + QJ63 steels. The content of pro-eutectic ferrite can be limited to $<25 \%$ in the weld metals. Thus the impact toughness in the HQ130 + QJ63 steel welds can meet the requirements for application in engineering machines. 


\section{Acknowledgement}

The work was supported by the Foundation of National

Key Laboratory of Advanced Welding Technology, Harbin Institute of Technology and National Natural Science Foundation of China (No. 50071028).

\section{References}

Farrar R A and Harrison P L 1987 J. Mater. Sci. 223812 Grong O and Matlock D K 1986 Inter. Metals Rev. 3127
Jiao Fujie 1994 Trans. China Weld. Inst. 15207

Kluken A O 1991 Metall. Trans. A22 657

Li Yajiang, Zou Zengda and Chen Zhunian 1997 J. Iron \& Steel Res. 946

Liu S and Olson D L 1986 Welding J. 65139

Oldland P T et al 1989 Welding J. 68158

Wang Shiliang, Hu Weiping and Tang Bogang 1990 Trans. China Weld. Inst. 1181

Yin Shike et al 1987 Acta Metall. Sinica B23 266

Zhang Yufeng et al 1995 China Welding 498

Zou Zengda and Li Yajiang 1999 J. Iron \& Steel Res. 1143 